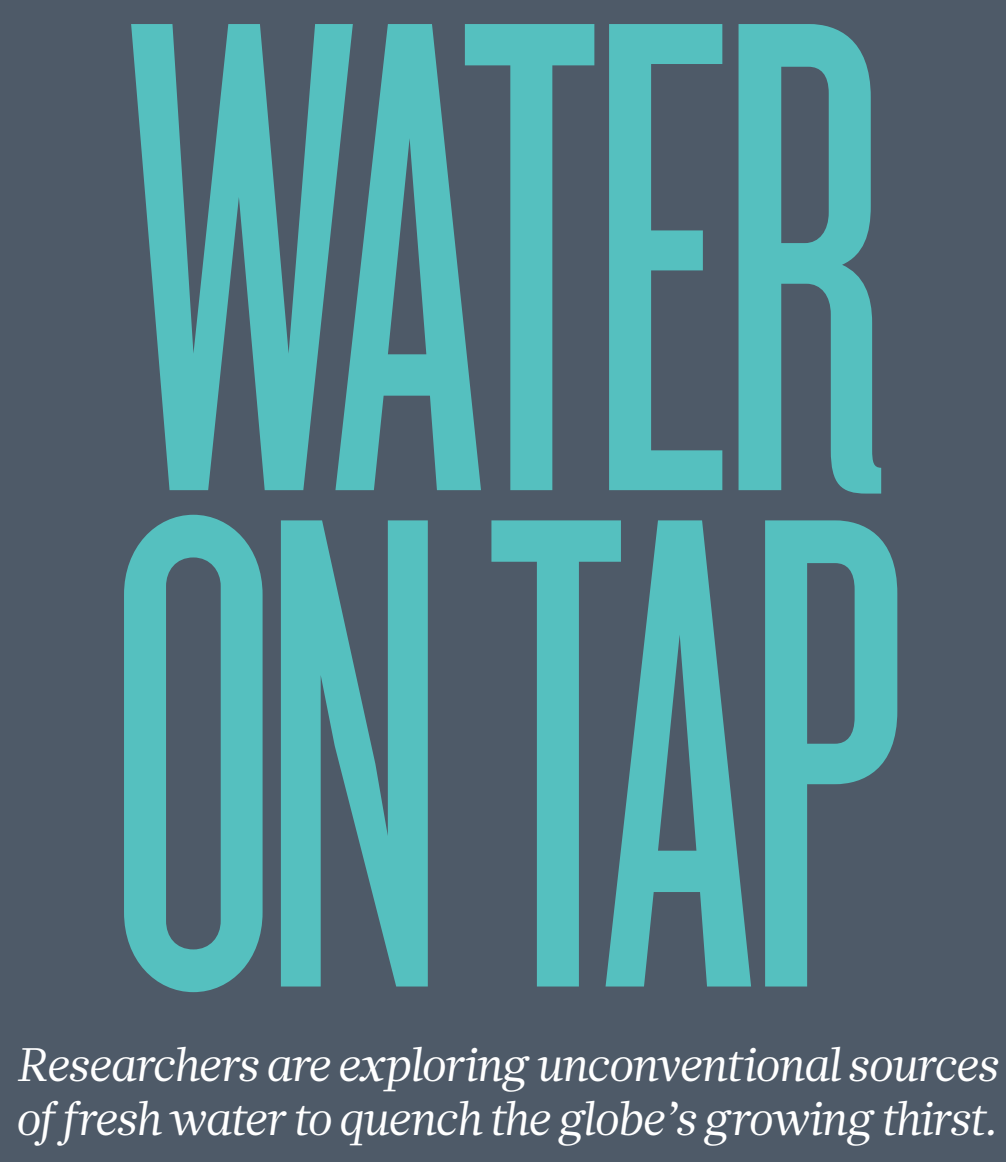

BY QUIRIN SCHIERMEIER $\mathrm{n}$ an effort to combat his country's long-standing water crisis, Iran's president took to Twitter last year. "We need plan to save water in agriculture, prevent excessive tap water use, protect underground sources of water and prevent illegal drilling," Hassan Rouhani tweeted in November.

Iran is far from alone. From the southwest United States to southern Spain and northern China, water shortages threaten many parts of the world. Nearly 800 million people lack access to safe drinking water and 2.5 billion have no proper sanitation.

The situation will probably get worse in coming decades. The world's population is expected to swell from 7 billion today to more than 9 billion by 2050 , even as climate change robs precipitation from many parched parts of the planet. If the world warms by just $2^{\circ} \mathrm{C}$ above the present level by the end of the century, which scientists believe is exceedingly likely, up to one-fifth of the global population could suffer severe shortages of fresh water.

"Even without global environmental change, feeding 9 billion people by 2050 will require an additional 2,000-3,000 cubic kilometres of fresh water in agriculture - more than the total global use of water in irrigation," says Johan Rockström, a specialist on water resources at Stockholm University and director of the Stockholm Resilience Centre. "This equates to nothing less than a new agricultural revolution. Novel approaches, such as water-harvesting practices, are absolutely critical in the future."

Most countries are seeking to expand access by tapping the underground aquifers that already supply the bulk of the fresh water for the global population. At the same time, some are experimenting with recycling waste water for agriculture and other uses. But many nations hope to tap unconventional sources - ranging from fog to the ocean - to quench their thirst. Some approaches involve billion-dollar deals; others are local efforts that require little in the way of costly technology. Here Nature looks at five ways to produce fresh water from unusual sources.
DESALINATION AT A COST

ike all Mediterranean countries, Israel receives most of its precipitation during the winter months. But last winter, almost no rain fell. In the past, such a drought would have caused severe problems for Israel's 8.2 million people. But thanks to the seawater desalination plants that Israel has built over the past decade, the country's taps did not run dry.

Israel's four large 'reverse osmosis' plants rank among the biggest and most efficient desalination facilities in the world. By next year, they are expected to provide more than 500 million cubic metres of fresh water per year - about half of Israel's needs. In 2012, IDE Technologies in Kadima, the company behind three of the existing Israeli plants, signed a deal to design a US\$1-billion desalination facility near Carlsbad, California. When completed by 2016, it will supply fresh water to about one-tenth of the 3.2 million people living in San Diego county.

A rapidly growing global industry, desalination has become in the past 20 years an essential source of fresh water for the Middle East, Australia, the United States, South Africa, Spain and, increasingly, India and China. In 2012, the total amount of installed desalination capacity exceeded 80 million cubic metres per day, enough to supply some 200 million people.

"With nearly half of the global population living within 100 kilometres of the ocean coast, you just can't avoid desalination," says Gary Amy, director of the Water Desalination and Reuse Center at the King Abdullah University of Science and Technology (KAUST) in Thuwal, Saudi Arabia. "Desalination is here to stay and it will inevitably become bigger."

But by any method, desalination consumes much more energy than conventional water sources. It takes just over 3 kilowatt hours (kWh) of energy to produce 1 cubic metre of potable water at the most efficient commercial reverse osmosis desalination plants - where pre-filtered sea water is forced under pressure through a series of semi-permeable membranes. A process that evaporates ocean water in thermal plants requires about $10 \mathrm{kWh}$ to produce the same amount of potable water. Some oil-rich countries do not mind the high price: Saudi Arabia's desalination industry, for example, currently burns some 300,000 barrels of oil per day.

Engineers are trying to improve reverse-osmosis technology using components such as lowenergy pumps and advanced membranes. Some are experimenting with membranes made of graphene to replace the polymers currently used. And efforts are under way globally to shift from fossil fuels to renewable energies in the desalination process.

Even with those advances, desalination will remain costly, says Maria Kennedy, a water-treatment specialist at the United Nations' Institute for Water Education in Delft, the Netherlands. "Nobody decides to do desalination unless they're out of other options." 


\section{GREENING THE DESERT}

griculture uses more than two-thirds of

A Earth's fresh water, so the idea of a farming practice that produces more water and energy than it consumes seems too good to be true. But in the desert of Qatar, scientists are showing that salt water and sunlight can yield food and clean water in a self-sustaining cycle.

The Sahara Forest Project (SFP), a Norwegian company launched in 2009 and supported by the Oslo-based fertilizer company Yara and the Qatar Fertilizer Company of Mesaieed, operates an \$8.5-million pilot facility outside Doha. Last year, the 700-square-metre greenhouse produced a crop of vegetables comparable to that of commercial greenhouses in Europe, according to SFP.

Greenhouses normally trap heat, but the reverse is required in hot places such as Qatar. At the SFP facility, sea water does the trick. The water, piped from the ocean just 100 metres away, trickles over a lattice at the windward side of the greenhouse. As the water evaporates, it humidifies the air entering the greenhouse and cools it by some $10^{\circ} \mathrm{C}$, creating an indoor climate suitable for growing vegetables such as cucumbers and tomatoes. Other crops, such as barley, salad rocket and useful desert plants, grow between hedges downwind of the greenhouse.

When the desert cools at night, water condenses on surfaces inside the greenhouse and is collected for irrigation and drinking. A desalination facility at the site produces further fresh water. And the electricity needed to run the entire installation comes from solar power.

Joakim Hauge, chief executive of the SFP in Oslo, believes that the concept can be scaled up to create green oases in desert climates that are otherwise hostile to farming. "With

\section{Agriculture uses more than two-thirds of Earth's fresh water.}

60 hectares of greenhouse production we could match the yearly import of cucumbers, tomatoes, peppers and aubergines to Qatar," he says.

The company is working with the government of Jordan to set up a 20-hectare pilot facility, including a commercial greenhouse unit and a research and innovation centre, in Aqaba. A larger commercial facility, says Hauge, would be able to produce excess electricity that could be exported to the grid.

The concept might work in any dry and sunny location that is near sea level, and therefore has low pumping costs. Even so, saltwater greenhouses remain an experiment for now, says Nina Fedoroff, director of the Center for Desert Agriculture at KAUST. "The concept is intriguing," she says. "But it is still a rather pricey way of producing food that might not gain huge commercial traction."

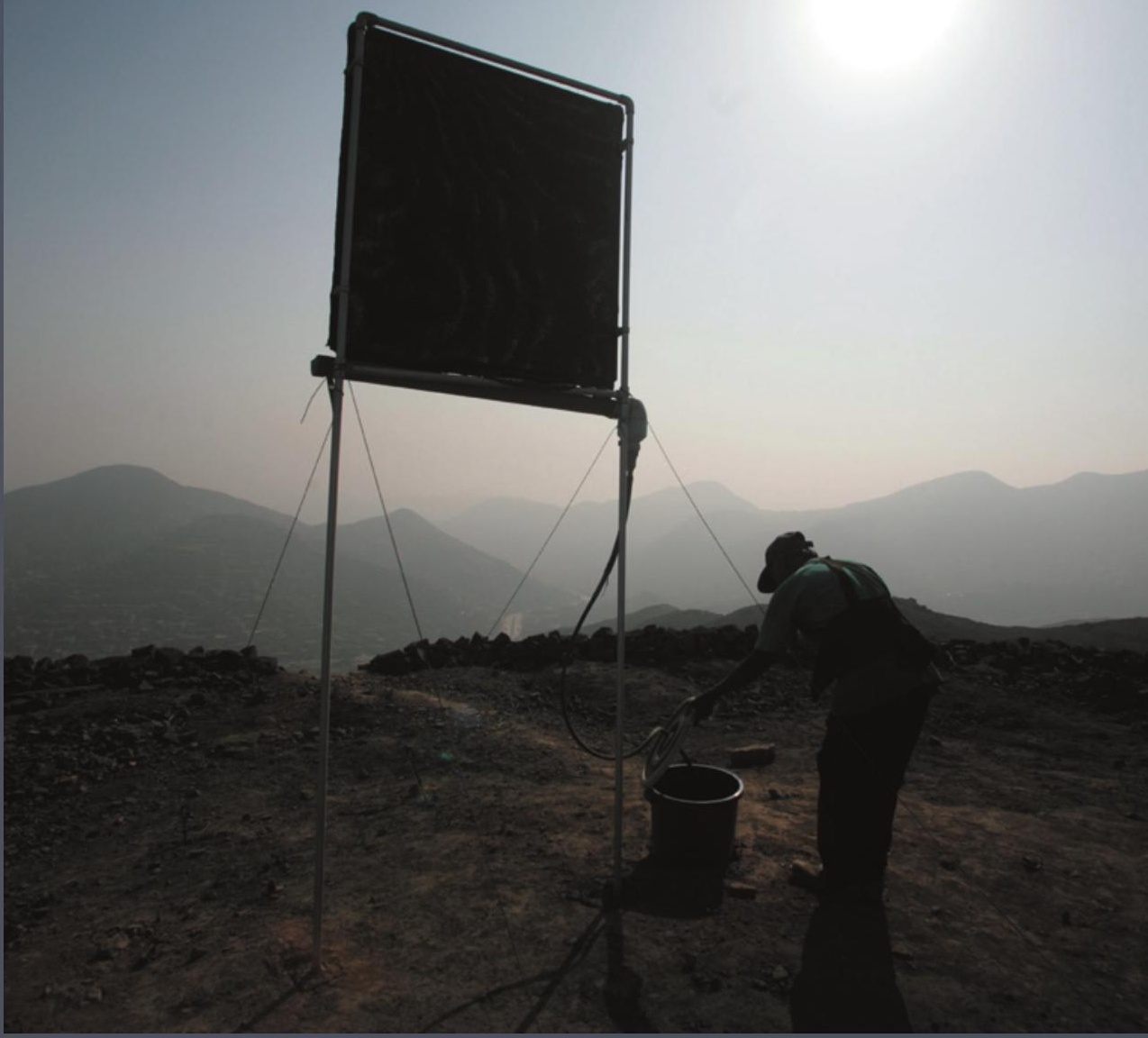

\section{FOG HARVESTING}

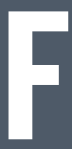

or as long as people can remember, women in the small mountain village of Tojquia, Guatemala, have had to trek down to the valley bottom during the dry winter months and haul fresh water back uphill to their families. But now they can get their
A fog collector in the hills above Lima, Peru. water by wringing moisture from the fog that often envelops their community.

One cubic metre of fog can contain up to 0.5 grams of liquid water, and harvesting it is relatively easy. A large vertical mesh panel can collect water droplets as the wind pushes clouds of moisture through its fibres. Tiny at first, the droplets coalesce and grow, then run into a gutter at the bottom and into a storage tank.

At 3,300 metres above sea level, where winters are windy and dry but often foggy, Tojquia is an ideal site for this technique. With the help of researchers from the non-profit FogQuest project in Kamloops, Canada, the residents of Tojquia have installed 35 collectors since 2006. These produce an average of 6,300 litres of potable water per day - enough for about 30 families during the dry season — and considerably more in the wet season when rainwater, too, is collected in the storage tanks.

Fog collection is catching on in seasonally dry regions that lack other sources of fresh water. The first simple mesh panels were built in the 1960s in the port town of Antofagasta in northern Chile. Today, 35 countries are using the technique, particularly along the Pacific coast of South and Central America, in the Atlas Mountains in Morocco and on the high plateaux of Eritrea and Nepal.

Improvements could come from advanced mesh materials, such as the permeable fibres developed by scientists at the Massachusetts Institute of Technology in Cambridge; when tested in Chile, these collected fog at a rate five times that of conventional mesh. And in the Namib Desert in Namibia, three-dimensional meshes developed at the Institute of Textile Technology and Process Engineering in Denkendorf, Germany, have achieved up to three times higher water yields than normal meshes.

Even with those kinds of gains, fog harvesting will not solve Chile's - or any other country's - water shortages. But it can provide a simple and sustainable method of producing fresh water in semi-arid regions that are short of other options, says Otto Klemm, a climatologist at the University of Münster in Germany.

"If the climatic conditions are right — and, importantly, if local people are trained to independently maintain the facilities," he says, "it does have the potential of supplying rural communities with precious fresh water year-round."

Quirin Schiermeier reports for Nature from Munich in Germany. 